\title{
Purple witchweed (Striga hermonthica) germination and seedbank depletion under different crops, fallow, and bare soil
}

\author{
THOMAS A. VAN MOURIK ${ }^{1 \star}$, TJEERD J. STOMPH ${ }^{2}$ and ALISTAIR J. MURDOCH ${ }^{3}$ \\ ${ }_{1}^{1}$ International Crops Research Institute for the Semi-Arid Tropics-Bamako, Bamako, Mali, ${ }^{2}$ Center for Crop Systems \\ Analysis, Wageningen University, Wageningen, The Netherlands and ${ }^{3}$ Department of Agriculture, University of Reading, \\ Reading, UK
}

\begin{abstract}
Seedbank density is an important aspect that determines the amount of damage that the parasitic weed, purple witchweed (Striga hermonthica; hereafter, called "Striga"), causes on its crop hosts. The seedbank depletion of Striga was measured in Mali and Niger during the 2004 rainy season under the host crops, pearl millet and sorghum, the non-host crops, cowpea and sesame, the intercrops of pearl millet or sorghum with cowpea or sesame, and fallow with or without weeding. Two methods were used and compared; namely, a seed bag method and a soil-sampling method. The fate of the seeds was assessed by a seed press test. Seed germination, as determined by the presence of empty seed coats, contributed most to the seedbank depletion of Striga under a variety of crop covers and fallow. The highest seedbank depletion was found under the monocultures of the host crops. The intercrops of the host and non-host crops caused less seedbank depletion, followed by the monocultures of the non-host crops, fallow, and bare soil. The seed bag method and the soil-sampling method yielded similar percentages of seedbank depletion, while the former allowed for distinguishing between the germinated and diseased seeds. The results suggest that, although all the tested crop species can cause the seed germination and seedbank depletion of Striga, management by using host cereal crops causes the highest amount of germination and has the highest potential to deplete the soil seed bank, provided that seed production is prevented.
\end{abstract}

Keywords: germination stimulant, pearl millet, population dynamics, seed death, sorghum, suicidal germination.

The hemiparasitic weed, purple witchweed (Striga hermonthica [Del.] Benth.; hereafter, called "Striga"), infects staple food cereals in sub-Saharan Africa and causes considerable yield losses in sorghum (Sorghum bicolor [L.] Moench), millet (Pennisetum glaucum [L.] R. Br.), and maize (Zea mays L.) (Gressel et al. 2004). For annual noxious weeds, such as Striga spp., the persistence of the soil seed bank proves to be the main problem in their control and management. Reliable estimates of seedbank

Communicated by C.C. Baskin.

^Correspondence to: Thomas A. Van Mourik, ICRISAT-Bamako, BP. 320, Bamako, Mali.

Email:tomvanmourik@yahoo.com

Received 29 December 2010; accepted 5 April 2011 depletion rates are therefore essential to understand weed population ecology and to design effective long-term management strategies (Westerman et al. 2007; Van Mourik et al. 2008).

Seed death due to aging, pathogenic fungi, germination, or seed predation depletes the seed bank. It is assumed that the seeds of Striga spp. can stay viable for long periods in the soil because, in the USA, 15\% and 1\% of Striga asiatica seeds were still viable after 12 years of burial in the soil at depths of $60 \mathrm{~cm}$ and $15 \mathrm{~cm}$, respectively (Bebawi et al. 1984). However, the high depletion rates of $>50 \%$ over one or two rainy seasons that have been reported in several studies on Striga in Africa cannot be attributed only to seed aging (Oswald \& Ransom 2001; Gbéhounou et al. 2003; Murdoch \& Kunjo 2003). These studies suggested that either 
infection of the seeds or germination in response to root exudates or microbial activity that led to ethylene production and the subsequent seed germination of Striga was responsible for the observed high seedbank depletion rates. In these studies, the cause of the seed loss or the relative importance of the two processes leading to seedbank depletion could not be determined by the methods and analyses that were used. The root exudates that were mentioned are chemical stimulants that trigger the germination of Striga seeds after a period of preconditioning (Vallance 1950). Although both the roots of the hosts and the non-hosts exude these chemicals (Egley 1972), when a non-host plant triggers the germination of Striga seeds, the seedlings are unable to attach to the root and they die; hence, the term "suicidal germination".

The potential of crop rotation with non-host plants to deplete the Striga soil seed bank by suicidal germination has been assessed in several laboratory experiments (Khan et al. 2002; Emechebe et al. 2003; Gbéhounou \& Adango 2003; Olupot et al. 2003) and under field conditions (Oswald \& Ransom 2001; Khan et al. 2002; Gbéhounou \& Adango 2003; Murdoch \& Kunjo 2003). Great variability in the seed germination was found during in vitro experiments in the laboratory (Emechebe et al. 2003) and consistent comparisons between the non-host and host crops often were lacking (Gbéhounou \& Adango 2003). When the non-host and host crops were compared, seed germination was higher in response to the host roots (i.e. maize and sorghum) than to the non-host crop roots (i.e. cowpea [Vigna unguiculata (L.) Walp.], soybean [Glycine max (L.) Merr.], and Celosia argentia L.), with the exception of cotton (Gossypium hirsutum L.) and silverleaf desmodium (Desmodium uncinatum [Jacq.] DC.), which evoked germination responses that were comparable to sorghum and maize (Khan et al. 2002; Emechebe et al. 2003; Olupot et al. 2003). It has been suggested that the variation in the depletion of the Striga soil seed bank is accounted for by these differences in the stimulation of suicidal germination (Oswald \& Ransom 2001; Khan et al. 2002; Abunyewa \& Padi 2003; Murdoch \& Kunjo 2003). It appears from the literature that quantitative information on Striga seedbank depletion under field conditions remains ambiguous, limited, and the processes behind it are poorly understood.

Obtaining accurate estimates of the means of seedbank depletion is difficult and the methods of measuring seedbank depletion directly or indirectly are still in development (Ishikawa-Goto \& Tsuyuzaki 2004; Fenner \& Thompson 2005; Van Mourik et al. 2005). Two methods have been used to measure Striga seed germination or mortality in the soil; namely, the seed bag burial method (Eplee 1975) and the soil-sampling technique
(Hartman \& Tanimonure 1991). To our knowledge, the two methods never have been compared in a single experiment. The advantage of the seed bag burial method is the placement of a known quantity of seeds at a known depth and location in a field, the easy retrieval of the seeds, and an assessment of the possible causes of seed death (Van Mourik et al. 2003). The disadvantages are the unnatural exposure environment (a nylon mesh bag in the soil) and the close proximity of a large number of seeds, which increases the chance of seed mortality due to infection by pathogenic fungi (Van Mourik et al. 2005). However, decreasing the seed density within a bag by mixing sand with the seeds has been shown to decrease the mortality due to pathogens and allows other means of depletion to be quantified (Van Mourik et al. 2005). Three classes of seeds are observed on retrieval of the seed bags: seeds with a firm and white endosperm, empty seed coats, and seeds with an unstructured black content. The latter are considered to have died through pathogenic attacks (Van Mourik et al. 2003). Sauerborn et al. (1996) showed that Fusarium nyagamai could penetrate viable, intact Striga seeds and infect the endosperm, which gives support to the assumption that seeds with a black endosperm have been killed by fungal attack.

Incorporating Striga seeds into the soil and sampling after time intervals is an alternative way of assessing seedbank depletion that is closer to natural conditions than the seed bag burial technique. The drawbacks are the heterogeneity of the seed densities that are applied (with depth and location) and the laborious retrieval of the seeds (in the case of Striga seeds, this requires wet sieving of the soil and separation of the organic and inorganic material by flotation in a solution with a high specific gravity). Each method, therefore, has advantages and drawbacks; it is assumed that using both simultaneously will give further insight into their relative performance, accuracy, and limitations.

The hypotheses that were tested in this study were: (i) host crops, like sorghum and millet, will be more effective in stimulating Striga germination than non-host crops or fallow; (ii) an intercrop of a host and non-host crop will generate germination comparable to germination under a host crop; (iii) seedbank depletion will be lowest under bare soil because the level of germination will be minimal; and (iv) seed losses under bare soil mainly will be caused by biological attacks or physiological aging.

The aims of this study were to quantify the relative contribution of seed germination or seed death to seedbank depletion under host and non-host crops, intercrops of host and non-host crops, fallow, and bare soil (Striga management strategies) with an improved seed

(C) 2011 The Authors Journal compilation (C) 2011 Weed Science Society of Japan 
Table 1. Site and experiment details

\begin{tabular}{|c|c|c|c|c|}
\hline Site (coordinates) & $\begin{array}{l}\text { Plot } \\
(\mathrm{N})\end{array}$ & $\begin{array}{l}\text { Sowing } \\
\text { date }\end{array}$ & $\begin{array}{l}\text { Annual rainfall } \\
\text { (mm) } \dagger\end{array}$ & Soil texture and type \\
\hline Samanko, Mali $\left(12^{\circ} 54^{\prime} \mathrm{N}, 8^{\circ} 54^{\prime} \mathrm{W}\right)$ & 4 & 26 June 2004 & 950 & Sandy loam, ferruginous tropical soil \\
\hline Sadore, Niger $\left(13^{\circ} 15^{\prime} \mathrm{N}, 2^{\circ} 17^{\prime} \mathrm{E}\right)$ & 6 & 6 June 2004 & 560 & $\begin{array}{l}\text { Sandy, silicious Isohypothermic Psammentic } \\
\text { Paleustalf }\end{array}$ \\
\hline
\end{tabular}

† Annual rainfall is the 10 year average.

bag burial method and to compare the estimates of seedbank depletion from the seed bag burial method to the estimates that were obtained with the soil-sampling method, in which the soil was inoculated with Striga seeds and subsequently sampled for seed extraction and analysis.

\section{MATERIALS AND METHODS}

\section{Sites, crop management, and treatments}

Two field experiments were carried out in 2004 at the experimental facilities of International Crops Research Institute for the Semi-Arid Tropics (ICRISAT) in Mali and Niger (Table 1). The Samanko site is in the Sudanian zone of Mali and the field in Sadore lies in the Sahel zone of Niger and both have a monomodal rainfall pattern. At each site, all the crops were sown at the same time and weeding and tillage were carried out before sowing (Table 2). The planting distances were $0.8 \mathrm{~m}$ between rows and $0.6 \mathrm{~m}$ within rows for the host crop and $0.4 \mathrm{~m}$ between rows and 0.6 within rows for the non-host crops. The plots without host crops measured $1.6 \mathrm{~m} \times 3.6 \mathrm{~m}$, containing three rows of the non-host crop if present. All the plots with a host crop measured $3.2 \mathrm{~m} \times 3.6 \mathrm{~m}$, with the intercrop sown between and within rows around the two central rows of the four host crop rows. Fertilizer (NPK, 17:17:17) was applied at a rate of $100 \mathrm{~kg} \mathrm{ha}^{-1}$ as a basal dressing 10 days prior to sowing at the Mali site only.The crops in Niger received no fertilizer, with the exception of the treatment with pearl millet and an organic amendment (cow manure). The sowing dates in Mali and Niger were 6 June 2004 and 26 June 2004, respectively. The cereal and non-host crop stands were thinned to one plant per stand after 3 weeks. In Mali, the level of cowpea mortality was high during the first 6 weeks after sowing and the stands were twice resown and treated with the insecticide, carbofuran (Furadan; STEPC, Abidjan, Ivory Coast), and the fungicide, metalaxyl (Apron+; Syngenta, Abidjan, Ivory Coast). The plots were weeded once by hoe 3 weeks after sowing, after which the plots were manually weeded to remove all the weeds other than Striga every 2 weeks. Two exceptions were the bare soil control, which was manually weeded weekly from the date of sowing, and the weedy fallow, which never was weeded.

Several Striga management strategies were evaluated for their potential to deplete the soil seed bank by (suicidal) germination or seed death. Although the sites differed in their level of rainfall and therefore the cereal host and species or cultivar of the non-host crops, the essential structure of the treatments composing the management strategies was similar. In Mali, the treatments that were tested were: bare soil, an unweeded fallow, a cowpea cultivar (Sangaranga; ICRISAT, Samanko, Mali), a late (long-duration) and local sorghum cultivar (Tiemarifing; ICRISAT, Samanko, Mali), an early (shortduration) sorghum cultivar (CSM63E; ICRISAT, Samanko, Mali), and an intercrop of a late sorghum cultivar with cowpea. In Niger, the treatments that were tested were: bare soil, an unweeded fallow, a sesame (Sesamum indicum L.) cultivar (Maradi local; ICRISAT, Sadore, Niger), a cowpea cultivar (TN5-78; ICRISAT, Sadore, Niger), a late and local pearl millet cultivar (Sadore local; ICRISAT, Sadore, Niger), an intercrop of pearl millet with sesame, an intercrop of pearl millet with cowpea, and pearl millet with an organic amendment at a rate of $0.2 \mathrm{~kg} \mathrm{~m}^{-2}$, equal to $2 \mathrm{t} \mathrm{ha}^{-1}$ (Table 2).

The Striga seeds that were used in Mali were collected in 2003 at the same site from a sorghum field (cv. Tiemarifing). In Niger, the seeds had been collected from a pearl millet field in Bengou in 1998. Both seed lots were stored in closed glass jars under laboratory conditions $\left(20-30^{\circ} \mathrm{C}\right)$ prior to use.

\section{Seed bag method}

Striga seeds were buried in bags, as described by Van Mourik et al. (2005), with $\sim 1000$ seeds in $25 \mathrm{~g}$ of coarse sand. Nylon gauze seed bags $(10 \mathrm{~cm} \times 10 \mathrm{~cm}$; mesh size: $90 \mu \mathrm{m}$ ) were buried at a $7 \mathrm{~cm}$ depth on a line in the center of each plot. The seed bags were buried 3 days prior to the sowing of the crops in Mali or at sowing 




(C) 2011 The Authors Journal compilation (C) 2011 Weed Science Society of Japan 
time in Niger. In Mali, 72 seed bags were buried, consisting of four replicates, three sampling times (40, 100, and 140 days after sowing, DAS), and six treatments. In Niger, 72 seed bags were buried, consisting of six replicates, two sampling times (40 and $100 \mathrm{DAS}$ ), and six treatments. In Niger, the number of bags was not sufficient to evaluate all the treatments. Thus, the pearl millet and an organic amendment and the pearl millet-sesame intercrop were not evaluated with the seed bag method. The treatment and sampling details are given in Table 2. The distance to the nearest host crop plant was $40 \mathrm{~cm}$ and the distance to the nearest non-host crop plant was $30 \mathrm{~cm}$. The bags were buried between the rows of the host and, where present, between the plants within the row of the intercrop or non-host crop.

The seed bags were dug up from the field, air-dried for 1 day, and the contents were emptied into $500 \mathrm{~mL}$ of sucrose solution ( $855 \mathrm{~g} \mathrm{~L}^{-1}$ distilled water, specific gravity of 1.2). While gently stirring the suspension for 2 min, the inorganic soil particles sank to the bottom, whereas the organic material (i.e. the seeds) started to float. The suspension was allowed to settle for at least $15 \mathrm{~min}$. Then, the upper $400 \mathrm{~mL}$ of suspension was filtered (mesh size: $100 \mu \mathrm{m}$ ) and rinsed with at least $500 \mathrm{~mL}$ of tap water. The seed coats of the seeds that were retained on the filter were bleached in a vial with $4 \mathrm{~mL} 1 \%$ sodium hypochlorite solution and $50 \mu \mathrm{L}$ Tween 20 (polyoxyethylene sorbitan monolaurate) for $2 \mathrm{~min}$, rinsed with tap water, and imbibed in tap water for at least $20 \mathrm{~min}$. The bleaching of the seed coat allowed for the scoring of the seeds with a black endosperm. After imbibition and bleaching, a subsample of between 100 and 150 seeds was examined under a stereomicroscope ( $\times 20$ magnification) (Zeiss, Germany) and scored for black seeds, empty seed coats, and intact light brown seeds. Earlier testing by Van Mourik et al. $(2003 ; 2005)$ revealed that, by lightly pressing the seeds (hence, the seed press test), the black seeds disintegrate, suggesting that microbial attack had led to seed death. The seeds that were empty when pressed were considered to have germinated (in rare cases, the degenerated parts of radicles extruding from such seed coats were observed). Firm seeds that had transparent or slightly whitish intact seed content were considered to be viable.

\section{Soil-sampling method}

The plots were inoculated with $0.21 \mathrm{~g}$ and $0.34 \mathrm{~g}$ of Striga seeds per $\mathrm{m}^{2}$ in Mali and Niger, respectively, corresponding to 41,900 and 60,000 germinable seeds, respectively (1000-seed weight, $0.004 \mathrm{~g} ; \sim 80 \%$ germinability in Mali and $\sim 70 \%$ germinability in Niger).
For each treatment plot, the Striga seeds were mixed with $100 \mathrm{~g}$ of coarse sand and broadcast manually, after which the soil was cultivated by a hand-held hoe to a depth of $15 \mathrm{~cm}$. The soil samples were taken with an auger $(8 \mathrm{~cm}$ diameter, $15 \mathrm{~cm}$ height) and the soil from a depth of 3-13 cm was selected. The samples were taken along a line in the center of each plot next to the seed bags 10 DAS, after which the holes were filled with soil from outside the plot. At 150 DAS, a bulked sample from three subsamples that had been taken in the center of each plot was analyzed because of a high variation in the number of seeds per sample at 10 DAS. This high variability was possibly a result of the uneven distribution of the seeds in the plot during the inoculation process. The soil samples were mixed thoroughly, air-dried, and a $100 \mathrm{~g}$ subsample was taken for analysis. The seeds were separated from the soil, as described by Hartman and Tanimonure (1991). The obtained sample, a mix of organic, fine debris and Striga seeds, was spread out over wet filter paper in lines and imbibed for $20 \mathrm{~min}$ before inspection with a stereomicroscope (×20 magnification). The numbers of intact and dead Striga seeds per sample were counted by the seed press test, as described above. However, large amounts of organic debris meant that the seeds could be distinguished only into two groups; namely, intact seeds and empty (dead) seeds. The efficiency of the seed extraction from the soil samples was estimated at $90 \%$, based on three sample analyses in which either 0 or 100 seeds were added to a $100 \mathrm{~g}$ air-dried soil sample.

\section{Calculations on the data and statistical analysis}

The percentages of the empty and the black seeds were calculated from the evaluation of the subsamples of 100150 seeds per seed bag per replicate. Using the data from the soil-sampling technique, the seedbank depletion was calculated as follows. First, the mean percentage of dead seeds was calculated for the samples from all treatments at 10 DAS ( $n=24$ in Mali and $n=42$ in Niger). Then, the individual percentages of the dead seeds per sample of a treatment taken at 150 DAS were subtracted from the mean of all the samples at 10 DAS to obtain the seedbank depletion (percentage) for this 140 day period.

The statistical analyses were carried out by using Genstat version 8 (VSN International, Hemel Hempstead, UK). Logit transformations were carried out on all the percentages of the empty and black seeds (seed bag method) or on the seedbank depletion (soil-sampling method) before an ANOVA with a test for orthogonal contrasts of different combinations of treatments. These contrasts are essentially identical between sites and test the hypotheses that were mentioned earlier. 


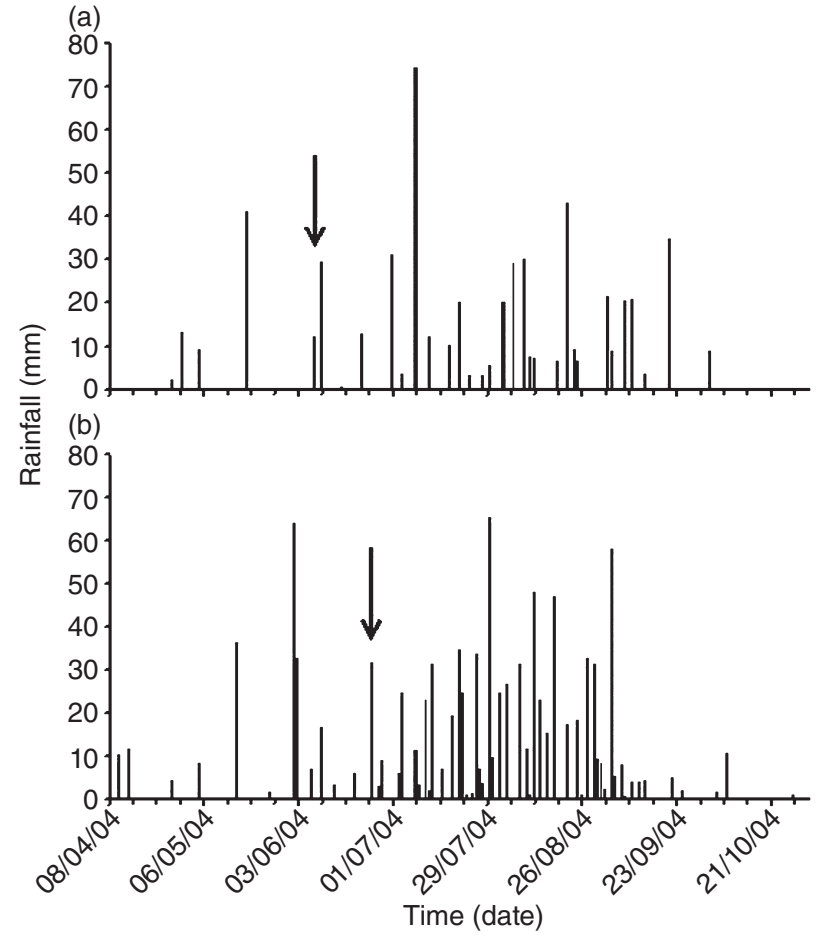

Fig. 1. Individual rainfall events during the rainy season of 2004 in (a) Sadore, Niger (2004 total: $562 \mathrm{~mm}$ ) and (b) Samanko, Mali (2004 total: $1009 \mathrm{~mm}$ ). The arrows indicate the date of sowing.

\section{RESULTS}

The rainfall pattern for the two sites varied as expected (Fig. 1). The total rainfall in Mali (1009 mm) was higher than the long-term average $(950 \mathrm{~mm})$, while the total rainfall in Niger $(562 \mathrm{~mm})$ was similar to the long-term average $(560 \mathrm{~mm})$. The sowing date in Mali was relatively late, considering the significant rains that preceded sowing (Fig. 1). The sowing date in Niger was relatively early because sowing was carried out with the first rains. In the fallow treatment at both sites, the broad-leaved plant species dominated in both the number of species, as well as the percentage ground cover $(>60 \%)$ of the plots. The fallow vegetation cover in the plots in Mali comprised broad-leaved species $(69.5 \%$, of which only $1.3 \%$ were leguminous species), grass species (18.9\%), Cyperus spp. $(2.6 \%)$, and bare soil (9\%).

Using the seed bag method, the majority of dead seeds at 140 DAS in Mali and at 100 DAS in Niger was found to be empty rather than black (infected) (Fig. 2). The large increase in the number of empty seeds in the soil where a late sorghum $(70.2 \%$ in Mali) or millet $(63.6 \%$ in Niger) was cultivated, compared to the bare soil where active roots were absent (20.8\% in Mali and $19.7 \%$ in Niger), indicated that the seedbank depletion during the rainy season was caused mainly by seed germination in reaction to the presence of the host root (Fig. 2).
Fig. 2. Changes in the percentage of black (ם), empty (回), and intact $(\square)$ Striga hermonthica seeds over a rainy season at two sites under bare soil or a host crop with the seed bag method: (a) and (c) Mali $(n=4)$ and (b) and (d) Niger $(n=6)$. The error bars represent the standard error of the mean.

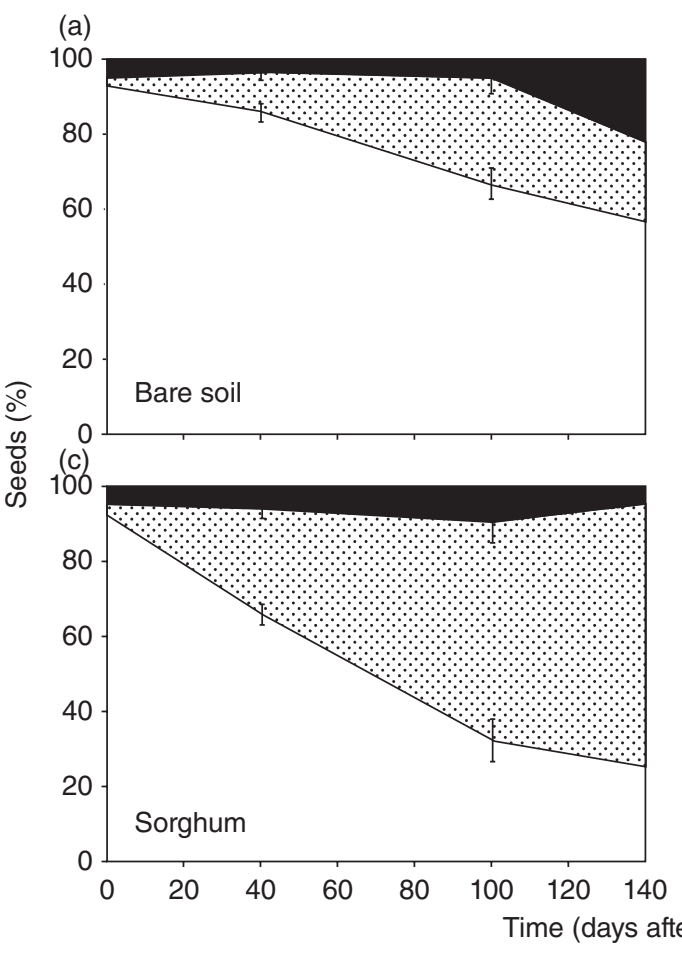

(b)

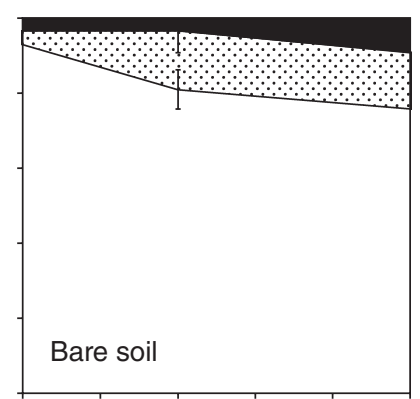

(d)

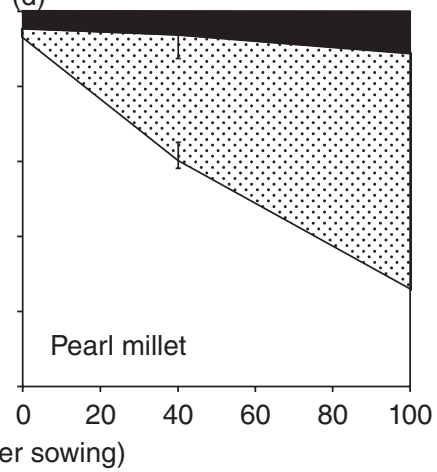

(C) 2011 The Authors Journal compilation (C) 2011 Weed Science Society of Japan 
Table 3. Percentage of the black (infected) and intact (viable) Striga hermonthica seeds 140 days after sowing (DAS) with the seed bag burial method and the number of dead and intact seeds 10 and 150 DAS with the soil-sampling method as a result of vegetative cover in Mali

\begin{tabular}{|c|c|c|c|c|c|c|}
\hline \multirow[t]{3}{*}{ Treatment } & \multirow{2}{*}{\multicolumn{2}{|c|}{$\begin{array}{l}\text { Seed bag } \dagger \\
140 \text { DAS }\end{array}$}} & \multicolumn{4}{|c|}{ Soil sampling } \\
\hline & & & \multicolumn{2}{|c|}{10 DAS } & \multicolumn{2}{|c|}{150 DAS } \\
\hline & Black seeds (\%) & Intact seeds $(\%)$ & Dead & Total & Dead & Total \\
\hline Bare soil & 22.10 & 57.10 & 5.40 & 19.20 & 4.00 & 13.20 \\
\hline Cowpea & 9.80 & 57.20 & 5.40 & 21.20 & 4.80 & 9.50 \\
\hline Fallow & 10.70 & 43.20 & 3.30 & 16.80 & 5.80 & 10.50 \\
\hline IC COW & 7.10 & 33.50 & 7.00 & 30.50 & 15.60 & 21.80 \\
\hline TIEM L $\ddagger$ & 4.00 & 25.70 & 5.70 & 23.20 & 10.30 & 13.50 \\
\hline CSM63E $\ddagger$ & 10.30 & 18.40 & 6.20 & 22.00 & 8.50 & 10.20 \\
\hline$P$-value & NS & 0.003 & NS & NS & 0.006 & NS \\
\hline d.f. & 23.00 & 23.00 & 23.00 & 23.00 & 23.00 & 23.00 \\
\hline SED & 4.94 & 8.38 & 6.38 & 7.61 & 1.62 & 4.66 \\
\hline
\end{tabular}

† Remaining percentage of seeds from the seed bag method pertains to the empty type (not shown); $\neq$ includes the sorghum host. The significance for the differences between the averages of the treatments was tested with a one-way ANOVA. CSM63E, short-duration sorghum cv. CSM63E; fallow, weedy fallow; IC COW, intercrop sorghum-cowpea cv. Sangaranga; NS, not significant; SED, standard error of difference; TIEM L, long-duration sorghum cv. Tiemarifing.

Only the seed bag method allowed for a distinction between germination and biological attack as potential causes of the seed loss. The percentage of black seeds was not significantly different between the cover treatments (Tables 3,4).

The percentages of empty and intact seeds were both significantly $(P<0.005)$ affected by the cover treatments at each site (Figs 3,4). The average percentages of the empty seeds ranged from 20.8\% (Mali, 140 DAS) and $19.7 \%$ (Niger, 100 DAS) under bare soil (no cover) to $71.4 \%$ in Mali under short-duration sorghum cover (Fig. 2) and 63.6\% in Niger under millet (Fig. 3).

The orthogonal contrasts revealed comparable differences at the two sites despite the different host and non-host crops and soil and rainfall conditions. Lower percentages of empty seeds were found under bare soil than for any treatment with vegetative cover $(P<0.001)$. The presence of a host cereal (early or late sorghum, pearl millet, sorghum-cowpea, or pearl millet-cowpea) resulted in higher percentages of empty seeds than a cover where a host cereal was absent (cowpea, sesame, or fallow) $(P<0.001)$. The percentage of empty seeds was higher under a pure cereal host stand (either sorghum or millet) than under the cereal-cowpea intercrop $(P=$ 0.035 and $P<0.001$, respectively). The sorghum duration had no effect on the percentage of empty seeds $(P=$ 0.821). The percentage of empty seeds in the seed bags from the vegetative cover treatments that did not include a cereal host (i.e. sesame, cowpea, and fallow) ranged from $33.1 \%$ (cowpea) to $46.1 \%$ (fallow) in Mali and from $30.6 \%$ (cowpea) to $44 \%$ (sesame) in Niger.

Using the soil-sampling method, there was no difference between the treatments in the number of dead seeds or in the total (dead and intact) number of seeds per soil sample that was taken 10 DAS at either site (Tables 3,4). In contrast, the number of dead seeds (but not the total number of seeds) differed significantly between the cover treatments $(P<0.01)$. The level of seedbank depletion ranged from 22.9\% (Mali) and 13.1\% (Niger) under bare soil to $83.4 \%$ under short-duration sorghum (Mali) and 60\% under the millet-sesame intercrop (Niger) and was significantly affected by the cover treatments $(P<0.001)$ (Figs 3,4). Higher seedbank depletion percentages were found under vegetative cover than under bare soil $(P<0.001)$. Also, higher seedbank depletion percentages were found under the treatments with a cereal host (short- and long-duration sorghum, millet, and sorghum-cowpea, millet-cowpea, or milletsesame intercrops) than under those without a cereal host (cowpea, sesame, and fallow) $(P<0.05)$. No significant difference was found when comparing the seedbank depletion percentages under either the pure host crops or the intercrops $(P>0.05)$ or when comparing the longand short-duration sorghum treatments $(P>0.05)$. Furthermore, no significant difference in the seedbank depletion percentages was found when comparing millet 
Table 4. Percentage of the black (infected) and intact (viable) Striga hermonthica seeds 140 days after sowing (DAS) with the seed bag burial method and the number of dead and intact seeds 10 and 150 DAS with the soil-sampling method as a result of vegetative cover in Niger

\begin{tabular}{|c|c|c|c|c|c|c|}
\hline \multirow[t]{3}{*}{ Treatment } & \multicolumn{2}{|c|}{ Seed bag $\dagger$} & \multicolumn{4}{|c|}{ Soil sampling } \\
\hline & \multicolumn{2}{|c|}{$100 \mathrm{DAS}$} & \multicolumn{2}{|c|}{10 DAS } & \multicolumn{2}{|c|}{150 DAS } \\
\hline & Black seeds $(\%)$ & Intact seeds (\%) & Dead & Total & Dead & Total \\
\hline Bare soil & 8.01 & 72.30 & 1.00 & 9.17 & 3.17 & 12.00 \\
\hline Sesame & 5.22 & 50.70 & 1.17 & 13.17 & 5.50 & 11.17 \\
\hline Cowpea & 5.10 & 64.30 & 2.00 & 11.67 & 3.66 & 8.33 \\
\hline Fallow & 3.44 & 53.30 & 0.83 & 9.33 & 5.00 & 8.67 \\
\hline IC COW & 6.25 & 50.90 & 1.33 & 8.00 & 4.67 & 7.67 \\
\hline IC SES $\ddagger$ & - & - & 1.67 & 11.00 & 4.34 & 6.17 \\
\hline SAD ORG $\ddagger$ & - & - & - & - & 3.66 & 6.33 \\
\hline SAD $\ddagger$ & 10.13 & 26.00 & 2.00 & 11.33 & 3.83 & 5.50 \\
\hline$P$-value & NS & $<0.001$ & NS & NS & $<0.001$ & NS \\
\hline d.f. & 35.00 & 35.00 & 47.00 & 47.00 & 47.00 & 47.00 \\
\hline SED & 2.865 & 5.78 & 1.473 & 2.756 & 1.473 & 9.746 \\
\hline
\end{tabular}

† Remaining percentage of seeds from the seed bag method pertains to the empty type (not shown); $\ddagger$ includes the millet host. The significance for the differences between the averages of the treatments was tested with a one-way ANOVA. Cowpea, cv. TN5-78; IC COW, intercrop millet-cowpea; IC SES, intercrop millet-sesame; NS, not significant; SAD, long-duration millet cv. Sadore local; SAD ORG, millet with an organic amendment; SED, standard error of difference; sesame, cv. Maradi local.

Fig. 3. Percentage of empty (germinated) seeds $(\square)$ from the seed bag method 140 days after sowing (DAS) and the percentage of seedbank depletion (ם) from the soil-sampling method 150 DAS in Mali. The error bars represent the standard error of difference $($ d.f. $=15)$. To the right side are the results of orthogonal contrast testing for the two methods. The gray bars indicate which groups of treatments (on the left side) are included in the comparison of the different groups. CSM63E, early sorghum; IC COW, intercrop sorghum-cowpea; TIEM L; late sorghum.

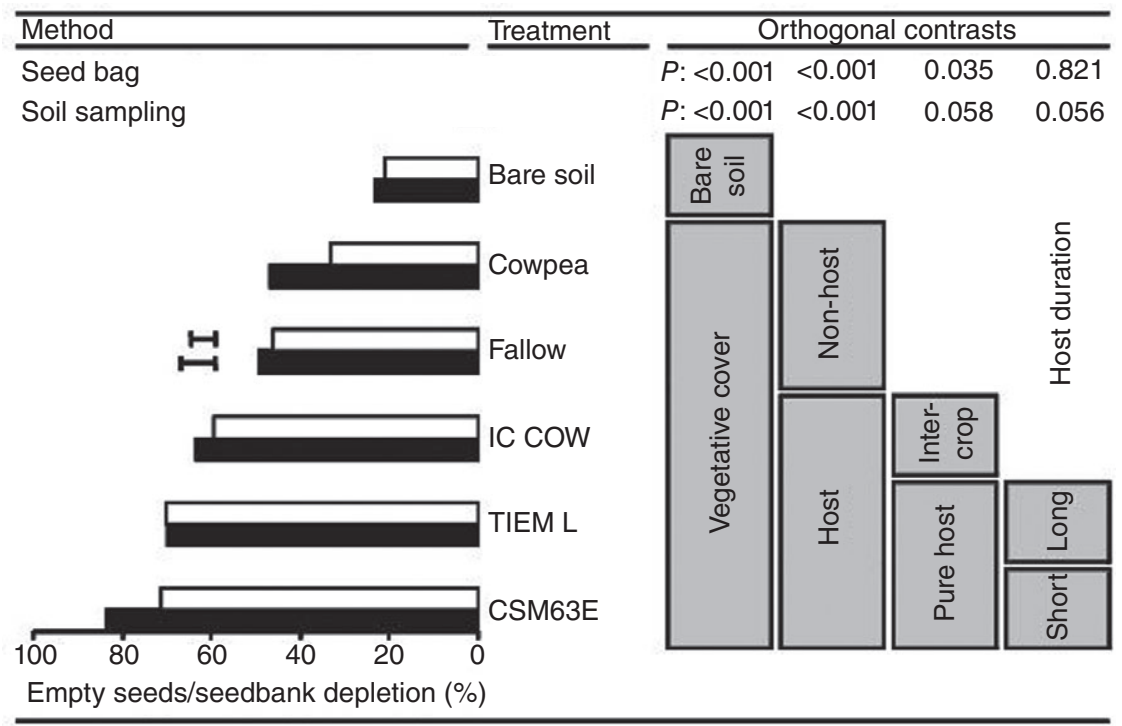

and millet with an organic amendment $(P=0.309)$ or when comparing the intercrops of millet-cowpea and millet-sesame $(P=0.511)$ (comparisons not shown in Fig. 4). Under vegetative cover, the treatments without a host crop led to a seedbank depletion rate of $46.6 \%$ (cowpea) to $49.4 \%$ (fallow) in Mali and of $32.9 \%$ (sesame) to $43.5 \%$ (fallow) in Niger.

\section{Comparison of the seed bag method and the soil-sampling method}

Although the number of seeds that was available for analysis was rather different between the seed bag and soil-sampling methods and although the seeds for the latter method were recovered from a depth profile 

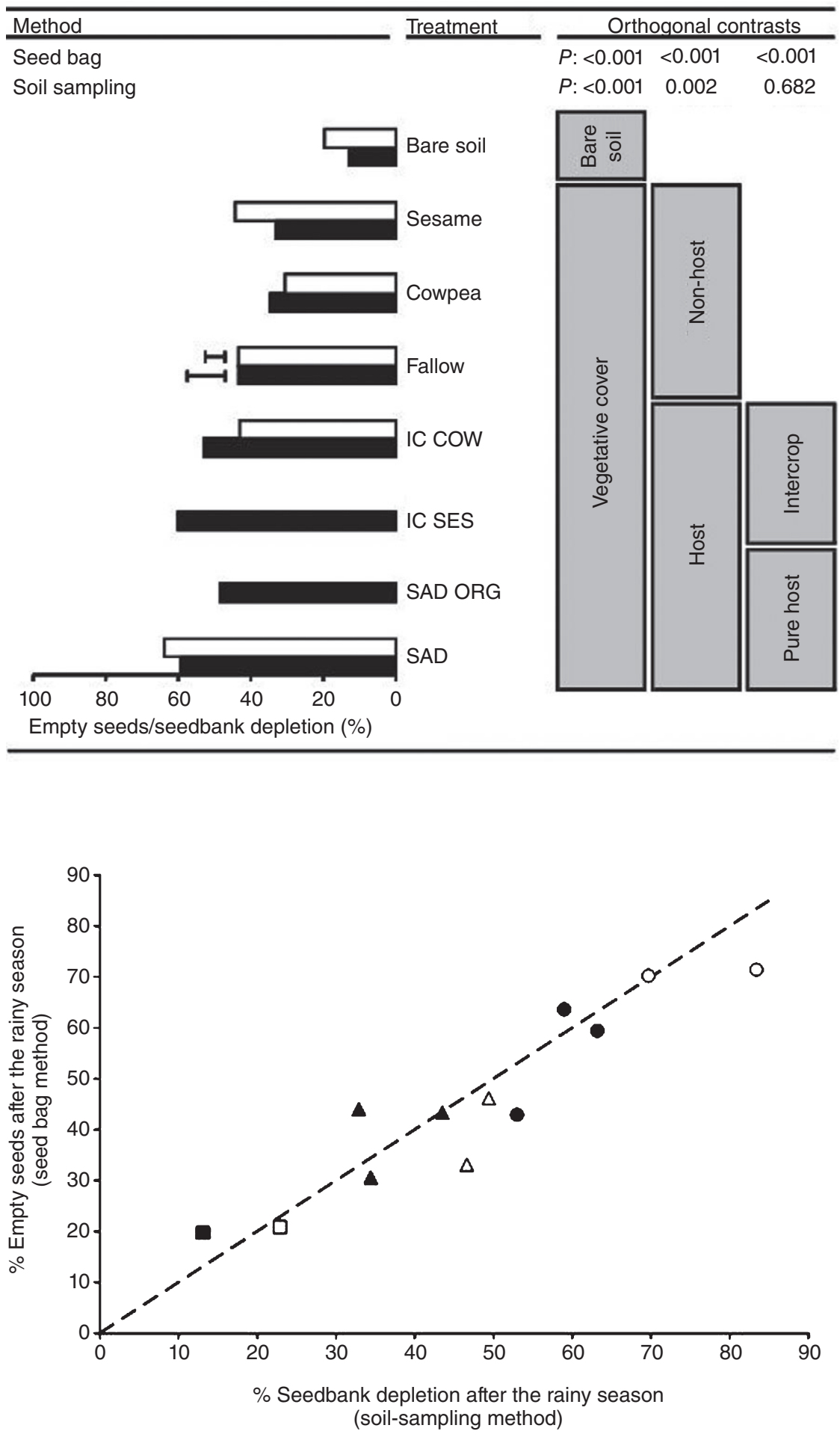

Fig. 4. Percentage of empty (germinated) seeds $(\square)$ from the seed bag method 100 days after sowing (DAS) and the percentage seedbank depletion (ם) from the soil-sampling method 150 DAS in Niger. The error bars represent the standard error of difference (d.f. $=35)$. To the right side are the results of orthogonal contrast testing for the two methods. The gray bars indicate which treatments are included in the comparison of the different groups. IC COW, intercrop millet-cowpea; IC SES; intercrop millet-sesame; SAD, long-duration millet; SAD ORG, long-duration millet with an organic amendment.

Fig. 5. Relationship between the percentage seedbank depletion from the soil-sampling method and the percentage of empty seeds from the seed bag method after one rainy season. The types of soil cover were grouped into bare soil ( $\square \mathbf{\square}$ ), vegetative cover without a cereal host being present $(\triangle \boldsymbol{\Delta})$, and vegetative cover with a cereal host being present ( $\bigcirc$ ). The open and closed symbols represent the data from Mali and Niger, respectively. ---, a hypothetical 1:1 relationship between the results of the analyses of the two methods. of between 3 and $13 \mathrm{~cm}$, the seedbank depletion percentages of the empty seeds with the seed bag method and those with the soil-sampling method were similar between treatments at the end of

(C) 2011 The Authors

Journal compilation C 2011 Weed Science Society of Japan the season (Figs 3-5). The averages of the treatments from the soil-sampling method and the seed bag method were close to a hypothetical 1:1 relationship (Fig. 5). 


\section{DISCUSSION}

At both sites, the host vegetation cover led to the highest percentage of empty seeds, with little difference between the sites. It is argued that most of the empty seeds arose from germination because so many more empty seeds were found in the soil where the vegetation, and thus the more active roots, was present, compared to the bare soil. Therefore, the percentage of empty seeds was used to estimate germination. The percentage of black seeds, which indicated seed death through biological agents (Van Mourik et al. 2005), remained low throughout the season, irrespective of the treatment. In these fields and with the seed densities used, seed death through biological attack therefore did not contribute greatly to seedbank depletion.

The treatments differed in their effectiveness in stimulating the seed germination of Striga. In order of decreasing effectiveness, they were: host cereal crops (sorghum or pearl millet) $>$ intercrops of host cereal with cowpea or sesame $>$ non-host vegetation (sesame, cowpea, or weeds) $>$ bare soil. It is difficult to compare the depletion rates that were obtained in this study with those from other studies because most other studies calculated the level of depletion over two rainy seasons. However, the non-host crops, cowpea and sesame, were no more effective in causing suicidal germination than was the weedy fallow (a mixture of monocotyledonous and dicotyledonous wild plants). Akiyama et al. (2005) indicated that strigolactones (a family of identified germination stimulants for Striga seeds) also stimulate the branching of arbuscular mycorrhiza. As symbiosis with arbuscular mycorrhiza is a widespread phenomenon in the plant kingdom, the chemical resemblance seems to imply that Striga-stimulating root exudates might be produced by a much wider spectrum of plant species than the limited number of non-host (trap) crops and host plants that have been tested thus far. For $S$. asiatica seeds, it also has been shown previously that the seeds germinate in response to stimuli that are not related to root exudates, such as mechanical (seed cuts and punctures) and chemical (sulphuric acid) scarification (Egley 1972). Therefore, it is possible that many other soil processes, such as the activity of soil microorganisms and soil perturbation, can evoke Striga seed germination to some extent. The results that are presented here support this suggestion because, in the absence of any vegetation (bare fallow), $\sim 20 \%$ of the seeds appeared to have germinated. Nevertheless, an additional $40-50 \%$ of germination was attributable to the presence of live plant roots, with a significantly higher response to the roots of the host plants, compared to the other plants. Interestingly, the effects of the natural fallow vegetation and non-host crops were similar. The fact that very similar data were observed at two contrasting sites, using two different host crops, intercrops, and inherently different fallow vegetation seems to indicate that these findings are of a morethan-local relevance and would seem to be relevant for the Sahel zone.

The modified seed bag method, as described in this article, and the soil-sampling method gave similar estimates of depletion (Fig. 5), but the soil-sampling method gave more variable results and was more labor-intensive. Also, the relatively limited number of Striga seeds per soil sample reduced the accuracy of the estimates of the percentages of dead and viable seeds. In addition, the seed samples from the seed bags had much less debris and ensured a sufficient number of seeds for a detailed analysis of the potential causes of seedbank depletion.

Seed bags can be produced easily and buried in on-farm trials where the inoculation of soil is not allowed and where the natural infestation is extremely heterogeneous. The seed bag method allows for other experimental manipulations, such as the burial depth, distance from the crop stand, and retrieval dates, and the non-host and host crops can be tested in their ability to stimulate (suicidal) germination in situ as an alternative to, or in addition to, in vitro techniques, such as agar gel assays (Hess et al. 1992) and cut-root assays (Emechebe et al. 2003; Gbéhounou \& Adango 2003).

Further research into the stages between germination and emergence at the field level is needed in order to understand this step of the life cycle and the intervention options that it could provide in terms of control.

\section{ACKNOWLEDGMENTS}

International Crops Research Institute for the SemiArid Tropics kindly provided the research facilities in Mali and Niger. The authors thank the late Idrissa Sangaré, Bakary Sidibé, Samuel Guindo, and Eva Weltzien of ICRISAT-Mali, Harouna Dodo of ICRISATNiger, and Wopke van der Werf for practical assistance, help, or advice on the article. This study was funded by the Netherlands Foundation for the Advancement of Tropical Research (NWO-WOTRO, project W-89-131).

\section{REFERENCES}

Abunyewa A.A. and Padi F.K. 2003. Changes in soil fertility and Striga hermonthica prevalence associated with legume and cereal cultivation in the Sudan savannah zone of Ghana. Land Degrad. Dev. 14, 335-343.

Akiyama K., Matsuzaki K.I. and Hayashi H. 2005. Plant sesquiterpenes induce hyphal branching in arbuscular mycorrhizal fungi. Nature $\mathbf{4 3 5}$, 824 .

(C) 2011 The Authors Journal compilation (C) 2011 Weed Science Society of Japan 
Bebawi F.F., Eplee R.E., Harris C.E. and Norris R.S. 1984. Longevity of witchweed (Striga asiatica) seed. Weed Sci. 32, 494-497.

Egley G.H. 1972. Influence of the seed envelope and growth regulators upon seed dormancy in witchweed (Striga lutea Lour.). Ann. Bot. 147, 755-770.

Emechebe A.M., Ahonsi M.O., Kureh I., Alabi S.O., Gbéhounou G. and Adango E. 2003. Ability of excised root and stem pieces of maize, cowpea and soybean to cause germination of Striga hermonthica seeds. Crop Prot. 22, 347-353.

Eplee R.E. 1975. Ethylene: a witchweed seed germination stimulant. Weed Sci. 23, 433-436.

Fenner M. and Thompson K. 2005. The Ecology of Seeds. Cambridge University Press, Cambridge.

Gbéhounou G. and Adango E. 2003. Trap crops of Striga hermonthica: in vitro identification and effectiveness in situ. Crop Prot. 22, 395-404

Gbéhounou G., Pieterse A.H. and Verkleij J.A.C. 2003. Longevity of Striga seeds reconsidered: results of a field study on purple witchweed (Striga hermonthica) in Benin. Weed Sci. 51, 940-946.

Gressel J., Hanafi A., Head G., Marasas W., Obilana A.B., Ochanda J. et al. 2004. Major heretofore intractable biotic constraints to African food security that may be amenable to novel biotechnological solutions. Crop Prot. 23, 661-689.

Hartman G.L. and Tanimonure O.A. 1991. Seed populations of Striga species in Nigeria. Plant Dis. 75, 494-496.

Hess D.E., Ejeta G. and Butler L.G. 1992. Selecting sorghum genotypes expressing a quantitative biosynthetic trait that confers resistance to Striga. Phytochemistry 31, 493-497.

Ishikawa-Goto M. and Tsuyuzaki S. 2004. Methods of estimating seed banks with reference to long-term seed burial. J. Plant Res. 117, 245-248.

Khan Z.R., Hassanali A., Overholt W., Khamis T.M., Hooper A.M., Pickett J.A. et al. 2002. Control of witchweed Striga hermonthica by intercropping with Desmodium spp., and the mechanism defined as allelopathic. J. Chem. Ecol. 28, 1871-1885.
Murdoch A.J. and Kunjo E.M. 2003. Depletion of natural soil seed banks of Striga hermonthica in West Africa under different integrated management regimes. In: Aspects of Applied Biology 69 (ed. by Bekker R.M., Forcella F., Grundy A.C., Jones N.E., Marshall E.J.P. and Murdoch A.J.). Horticulture Research International, Wellesbourne, UK, 261-268.

Olupot J.R., Osiru D.S.O., Oryokot J. and Gebrekidan B. 2003. The effectiveness of Celosia argentia (Striga "chaser") to control Striga on sorghum in Uganda. Crop Prot. 22, 463-468.

Oswald A. and Ransom J.K. 2001. Striga control and improved farm productivity using crop rotation. Crop Prot. 20, 113-120.

Sauerborn J., Dorr I., Abbasher A., Thomas H. and Kroschel J. 1996. Electron microscopic analysis of the penetration process of Fusarium nygamai, a hyperparasite of Striga hermonthica. Biol. Control 7, 53-59.

Vallance K.B. 1950. Studies on the germination of the seeds of Striga hermonthica 1: The influence of moisture treatment, stimulant-dilution and after-ripening on germination. Ann. Bot. 14, 347-363.

Van Mourik T.A., Stomph T.J. and Westerman P.R. 2003. Estimating Striga hermonthica seed mortality under field conditions. In: Aspects of Applied Biology 69 (ed. by Bekker R.M., Forcella F., Grundy A.C., Jones N.E., Marshall E.J.P. and Murdoch A.J.). Horticulture Research International, Wellesbourne, UK, 187-194.

Van Mourik T.A., Stomph T.J. and Murdoch A.J. 2005. Why high seed densities within buried mesh bags may overestimate depletion rates of soil seed banks. J. Appl. Ecol. 42, 299-305.

Van Mourik T.A., Bianchi F.J.J.A., Van Der Werf W. and Stomph T.J. 2008. Long-term management of Striga hermonthica: strategy evaluation with a spatio-temporal population model. Weed Res. 48 , 329-339.

Westerman P.R., Van Ast A., Stomph T.J. and Van Der Werf W. 2007. Long-term management of the parasitic weed Striga hermonthica: Strategy evaluation with a population model. Crop Prot. 26, 219-227. 